International Journal of Molecular Sciences

ISSN 1422-0067

www.mdpi.com/journal/ijms

Review

\title{
Molecular Pathology of Neuro-AIDS (CNS-HIV)
}

\section{Leslie Crews ${ }^{1}$, Christina Patrick ${ }^{2}$, Cristian L. Achim ${ }^{3}$, Ian P. Everall ${ }^{3}$ and Eliezer Masliah ${ }^{1,2, *}$}

1 Department of Pathology, University of California, San Diego / 9500 Gilman Dr. La Jolla, CA 92093, U.S.A.; E-Mail: lcrews@ucsd.edu

2 Department of Neurosciences, University of California, San Diego / 9500 Gilman Dr. La Jolla, CA 92093, U.S.A.; E-Mail: cpatrick@ucsd.edu

3 Department of Psychiatry, University of California, San Diego / 9500 Gilman Dr. La Jolla, CA 92093, U.S.A.; E-Mails: cachim@ucsd.edu (C.A.); ieverall@ucsd.edu (I.E.)

* Author to whom correspondence should be addressed; E-Mail: emasliah@ucsd.edu; Tel. +1 (858) 534-8992; Fax: +1 (858) 534-6232

Received: 9 February 2009; in revised form: 5 March 2009 / Accepted: 9 March 2009 / Published: 11 March 2009

\begin{abstract}
The cognitive deficits in patients with HIV profoundly affect the quality of life of people living with this disease and have often been linked to the neuro-inflammatory condition known as HIV encephalitis (HIVE). With the advent of more effective antiretroviral therapies, HIVE has shifted from a sub-acute to a chronic condition. The neurodegenerative process in patients with HIVE is characterized by synaptic and dendritic damage to pyramidal neurons, loss of calbindin-immunoreactive interneurons and myelin loss. The mechanisms leading to neurodegeneration in HIVE might involve a variety of pathways, and several lines of investigation have found that interference with signaling factors mediating neuroprotection might play an important role. These signaling pathways include, among others, the GSK3 $\beta$, CDK5, ERK, Pyk2, p38 and JNK cascades. Of these, GSK3 $\beta$ has been a primary focus of many previous studies showing that in infected patients, HIV proteins and neurotoxins secreted by immune-activated cells in the brain abnormally activate this pathway, which is otherwise regulated by growth factors such as FGF. Interestingly, modulation of the GSK3 $\beta$ signaling pathway by FGF1 or GSK3 $\beta$ inhibitors (lithium, valproic acid) is protective against HIV neurotoxicity, and several pilot clinical trials have demonstrated cognitive improvements in HIV patients treated with GSK3 $\beta$ inhibitors. In addition to the GSK3 $\beta$ pathway, the CDK5 pathway has recently been implicated as a mediator of neurotoxicity in HIV, and HIV proteins might activate
\end{abstract}


this pathway and subsequently disrupt the diverse processes that CDK5 regulates, including synapse formation and plasticity and neurogenesis. Taken together, the GSK3 $\beta$ and CDK5 signaling pathways are important regulators of neurotoxicity in HIV, and modulation of these factors might have therapeutic potential in the treatment of patients suffering from HIVE. In this context, the subsequent sections will focus on reviewing the involvement of the GSK3 $\beta$ and CDK5 pathways in neurodegeneration in HIV.

Keywords: HIV; encephalitis; NeuroAIDS; inflammation; GSK3ß; CDK5.

\section{Introduction}

The control and eradication of the neurological complications associated with AIDS continues to be an important goal in efforts toward improving the well-being of patients with HIV. In the central nervous system (CNS) of these patients, brain microglial cells are a primary reservoir for HIV-1 infection [1,2]. These immune-activated cells secrete neurotoxins and produce HIV-1 proteins that contribute to the development of HIV-associated cognitive impairment (HACI) [3]. This progressive neurologic disease is characterized clinically by cognitive deficits that profoundly affect the quality of life of people living with this condition. Cognitive impairment in patients with HIV infection has often been linked to HIV encephalitis (HIVE) [4], a neuro-inflammatory condition [2,5] characterized by the presence of HIV-infected microglial cells, formation of microglial nodules, multinucleated giant cells, astrogliosis, myelin loss and neurodegeneration [6,7].

With the advent of highly active antiretroviral therapies (HAART), the abundance of HIV in the brain and overt dementia has declined, however as the number of treated subjects with chronic HIV infection increases, the prevalence of HACI is actually rising, despite HAART [8-11]. It is now becoming apparent that these patients may be suffering from protracted forms of HIVE $[7,8]$ that might lead to more subtle cognitive alterations rather than to overt dementia $[1,4,12,13]$. Patients with protracted mild forms of HIVE sometimes display more severe neurodegenerative pathology characterized by the simplification of the synapto-dendritic structure of pyramidal neuronal populations in the neocortex, indicating that HIVE has transitioned from a subacute to a chronic condition [6]. Thus, identification of new targets that might protect the CNS from the toxic effects of HIV might be an important adjuvant therapy for patients with HACI.

\section{Molecular and cellular mechanisms of neurodegeneration in HIV Encephalitis}

The mechanisms leading to cognitive impairment and dementia in AIDS patients are complex and require further investigation. Various line of evidence indicate that when HIV-infected monocytes/macrophages activate neuro-inflammatory cells such as microglia and astrocytes [14-21], these cells produce chemokines, cytokines and neurotoxins that, in conjunction with secreted HIV proteins, damage the synapto-dendritic arbor of neurons [22], leading to neuronal dysfunction and cell death probably via apoptosis [23-32]. This model predicts that levels of HIV in the CNS might reflect the extent of the structural and functional pathology in the brain [33-35]. Most patients with florid HIVE display cognitive impairment that in some severe cases results in dementia [4]. However, about 
a quarter of patients with evidence of HIVE at autopsy clinically are neurologically un-impaired. Most cases with no significant neuropathology are cognitively un-impaired, nonetheless approximately one third of cases with no evidence of HIVE display cognitive alterations [4].

The neurodegenerative process in patients with HIVE is characterized by synaptic and dendritic damage [36] to pyramidal neurons [36], loss of calbindin-immunoreactive interneurons [37] and myelin loss [38]. While disruption of the cortico-cortico connections might result in learning and attention deficits, hippocampal pathology is linked to memory loss, and cortico-striatal damage results in motor alterations [39]. In addition to the damage to mature neuronal circuitries, recent studies have shown that HIV proteins might contribute to the neurodegenerative process by interfering with neurogenesis in the hippocampus [40-43]. Neurogenesis in the dentate gyrus is an active process in the mature CNS and plays a key role in synaptic plasticity, memory, and learning [44,45]. Environmental enrichment has been shown to stimulate neurogenesis and improve performance in memory tasks in mice [46-48]. The wnt [49] GSK3 $\beta$ and the cyclin-dependent kinase (CDK) signaling pathways [50] play an important role in this process. Therefore, the neurodegenerative process leading to cognitive alterations in HIV patients includes both: 1) damage to the mature synapto-dendritic apparatus of developed neurons and 2) impaired ability of NPCs in the hippocampal dentate gyrus to generate new neurons (Figure 1).

Figure 1. Mechanisms of HIV protein-induced neuronal damage. HIV protein-mediated activation of cell surface receptors (CXCR4, NMDA-R, Notch1) leads to alterations in signaling pathways such as GSK3 $\beta$ and CDK5. Under physiological conditions, these pathways modulate critical substrates involved in synaptic plasticity and neurogenesis, and dysregulation of these signaling cascades could result in synapto-dendritic damage and impaired neurogenesis.

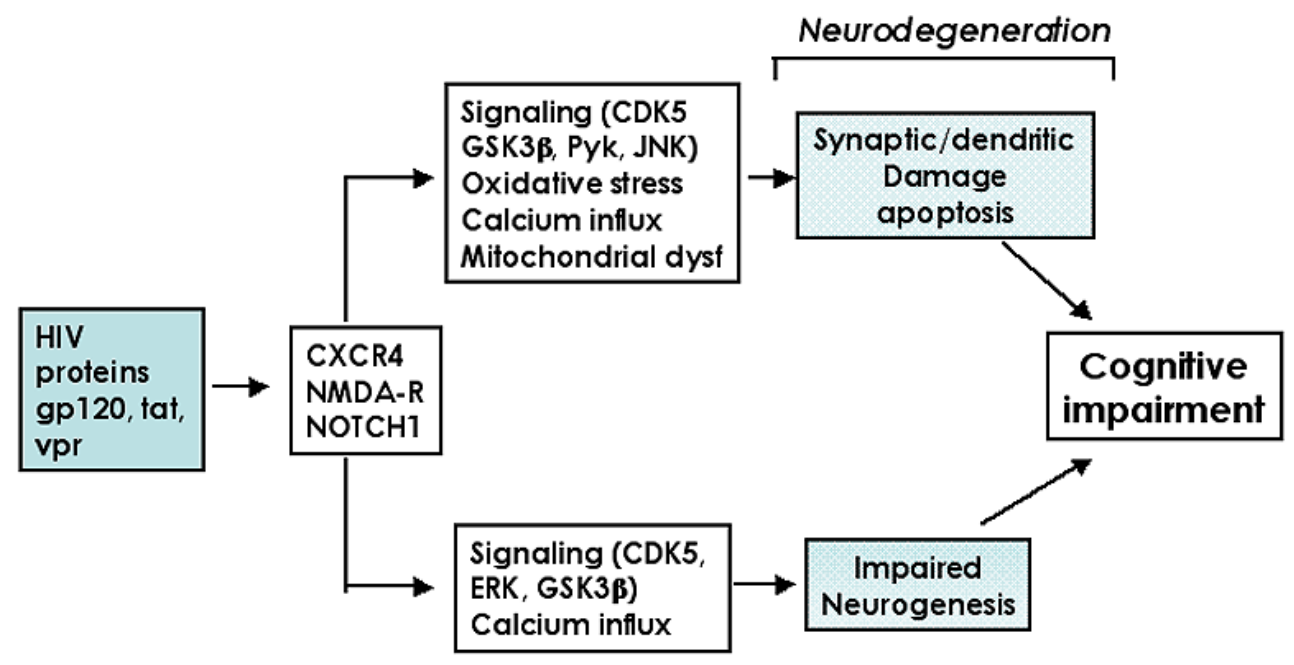

The mechanisms leading to neurodegeneration in HIVE might involve a variety of pathways including excitotoxicity [51,52], oxidative stress [23], mitochondrial dysfunction [53,54] and calcium dysregulation [55,56] (Figure 1). In addition, several lines of investigation have found that interference with signaling pathways mediating neuroprotection might also play an important role. Among them, previous studies have shown that HIV proteins abnormally activate the CDK5 [57,58], GSK3 $\beta$ [59,60] 
and ERK [61,62] signaling pathways, which otherwise are regulated by fibroblast growth factors (FGFs) [63,64]. In addition to direct activation of these signaling pathways, HIV proteins have been shown to trigger the release of neurotoxic products such as platelet-activating factor (PAF), which also contribute to dysregulation of signaling pathways such as GSK3 $\beta$ [65]. Furthermore, HIV proteins trigger neurodegeneration by activating signaling pathways involved in apoptosis such as RNAactivated protein kinase [66], Pyk2 [67], p38 and JNK [24,61,68]. Of these molecular pathways leading to neurodegeneration in patients with HIVE, the subsequent sections will focus on reviewing the involvement of the GSK3 $\beta$ and CDK5 pathways.

\subsection{Role of FGF1-mediated regulation of the GSK3 $\beta$ signaling pathway in the mechanisms of neurodegeneration and neuroprotection in HIVE}

Previous studies found that in patients with cognitive impairment and HIVE, neurodegeneration might be associated with a reduction in the expression of neurotrophic factors such as FGF1 [69]. In contrast, in a subset of patients with HIV with preserved cognitive performance, FGF1 levels are upregulated. Interestingly, neuronal populations prone to degenerate in patients with HIV are dependent on FGF1 and FGF2 and express FGF receptors and CXCR4 [6,63,70]. The FGFs belong to a family 13 trophic factors that are involved in neurogenesis [71] and angiogenesis [72]. Since FGF1 and 2 are expressed in the CNS in neurons vulnerable to the neurotoxic effects of HIV proteins [69], this indicates that the molecular pathways modulating FGF1 effects might be important mediators of the signaling involved in neurodegeneration and neuroprotection in patients with HIV [73].

In vitro studies in primary neurons and neuronal cell lines have shown that the neuroprotective effects of FGF1 and FGF2 are mediated by activation of PI3K-Akt that in turn inactivate GSK3 $\beta$ via phosphorylation at the Ser 9 residue [63,64]. In addition to FGF1 and FGF2, other growth factors that exert their effects via receptor tyrosine kinases also lead to inactivation of GSK3 $\beta$ through phosphorylation. These include growth factors such as insulin growth factor-1 (IGF-I), epidermal growth factor (EGF) and platelet-derived growth factor (PDGF) [74,75]. To further investigate the neuroprotective effects of GSK3 $\beta$ regulation by FGF1 in vivo, we generated lines of tg mice expressing the human FGF1 under a neuronal promoter (PDGF $\beta$ ).

Human FGF1 cDNA was obtained by reverse transcriptase polymerase chain reaction (RT-PCR) from human brains and cloned into PCRII vector (TA Cloning from Invitrogen, CA) and 100\% fidelity of nucleotide sequence was confirmed by dideoxy sequencing. Subsequently the FGF1 cDNA fragment was subcloned into the PDGF $\beta$ transgene cassette. The PDGF $\beta$ promoter was a gift of Dr. Tucker Collins at Harvard Medical School. The final construct contains the PDGF $\beta$ promoter, SV40 intron, hFGF1 cDNAs, and SV40 polyA (Figure 2A). Constructs were microinjected and 5 lines of founder mice were obtained. Of them, based on the levels of mRNA expression two transgenic lines (line 15 low expresser; line 12 moderate expresser) were selected. RPA and Western blot analysis showed that both lines expressed human (h)FGF1 at levels comparable to the levels in the human brain (Figure 2B-F). Immunocytochemical analysis confirmed that hFGF1 was primarily expressed by neurons in the neocortex, hippocampus and basal ganglia, regions selectively susceptible to the neurotoxic effects of HIV products. Both lines of hFGF1 tg mice were viable, bred well and the nervous system developed normally. To determine the effects of FGF1 expression on the GSK3 $\beta$ 
signaling pathway, immunoblot analysis was performed with an antibody against phosphorylated GSK3 $\beta$. This showed that in the mouse line expressing moderate levels of hFGF1 (line 12), levels of phosphorylated GSK3 $\beta$ (inactive form) were increased, while levels of pGSK3 $\beta$ in the low expresser line (15) were similar to nontg controls (Figure 2C).

Figure 2. Characterization of hFGF1 tg mice. (a) Construct expressing hFGF1 under the control of the PDGF $\beta$ promoter. (b) RPA analysis of FGF1 mRNA expression. (c) Immunoblot analysis of total FGF1 protein expression and inactivation of GSK3 $\beta$ in FGF1 tg mice. (d) Semi-quantitative analysis of hFGF1 mRNA levels. (e) Semi-quantitative analysis of mFGF1 mRNA levels. (e) Semi-quantitative analysis of total FGF1 protein expression by immunoblot.

A

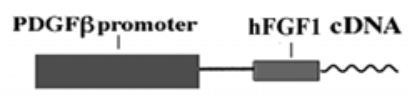

B
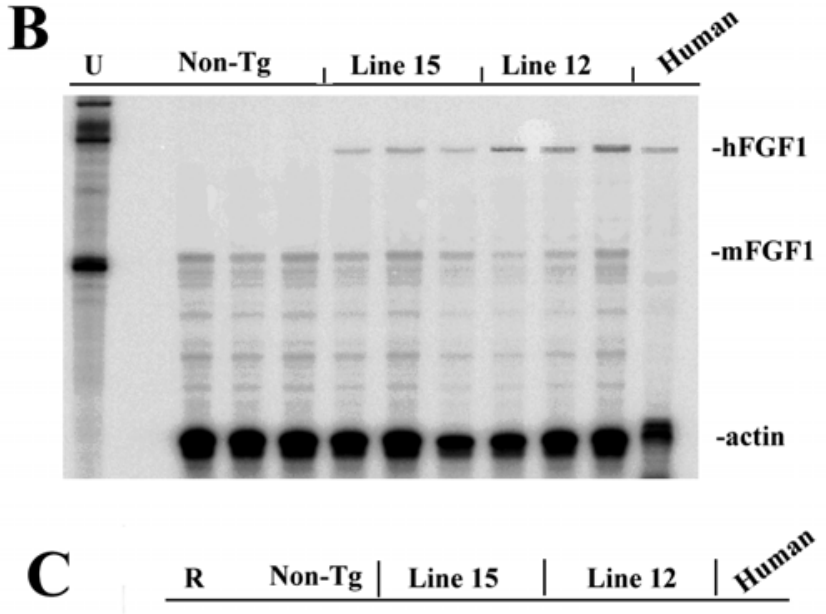

FGF1-

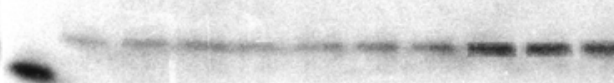

pGSK3 $\beta$ -
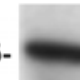

D

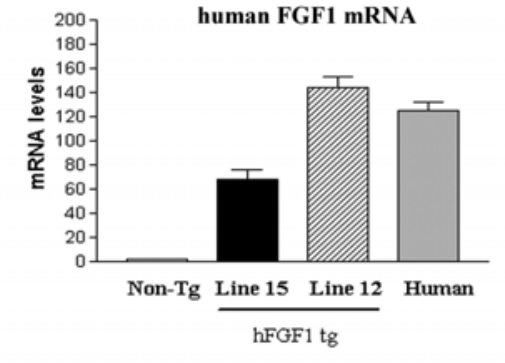

E

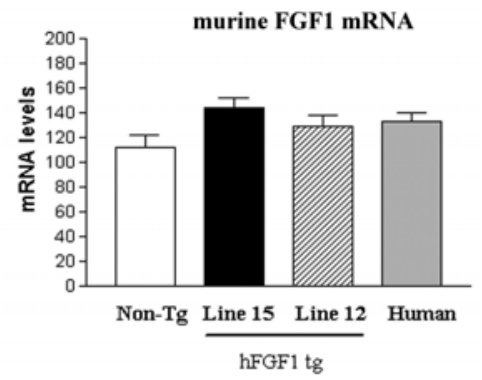

$\mathbf{F}$

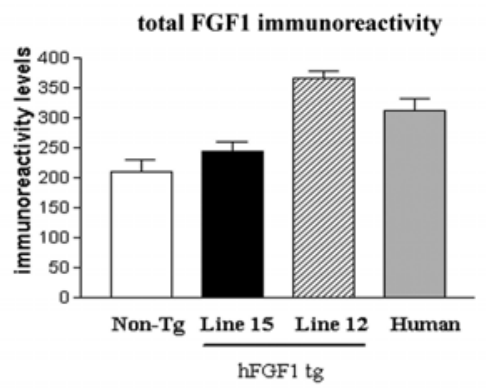

In order to test the hypothesis that hFGF1 protects against the neurotoxic effects of HIV products, tg mice ( 3 mo old, 5 per group) from lines 12 and 15 received intracerebral gp120 injections (1mM, total $2 \mu \mathrm{l}$ ) in the neocortex and hippocampus. In nontg mice (3 mo old, 5 per group), gp120 promoted significant neuronal damage and astrogliosis compared to nontg saline-treated mice (Figure 3). In hFGF1 tg mice from line 12 (moderate expresser) neurons were protected against the toxic effects of gp120, while line 15 mice (low expresser) were susceptible, supporting the contention that hFGF1 was bioactive and protected neurons in a dose-dependent manner, probably via inactivation of GSK3 $\beta$. 
Therefore, treatments directed at increasing the expression of FGF1 or targeting the signaling pathways affected, such as GSK3 $\beta$, might represent a possible neuroprotective strategy.

Figure 3. Protective effects of FGF1 expression against the toxic effects of HIV-gp120 in mice injected with gp120 protein. (a) Nontg mouse injected with saline. (b) A prominent lesion developed in nontg mice injected with gp120 protein. (c) hFGF1 tg mouse injected with saline. (d) In hFGF1 tg mice injected with gp120, the neurons are protected and no lesion is observed. (e) Semi-quantitative analysis of levels of MAP2 immunoreactivity in the hippocampus. (f) Semi-quantitative analysis of levels of MAP2 immunoreactivity in the cortex.
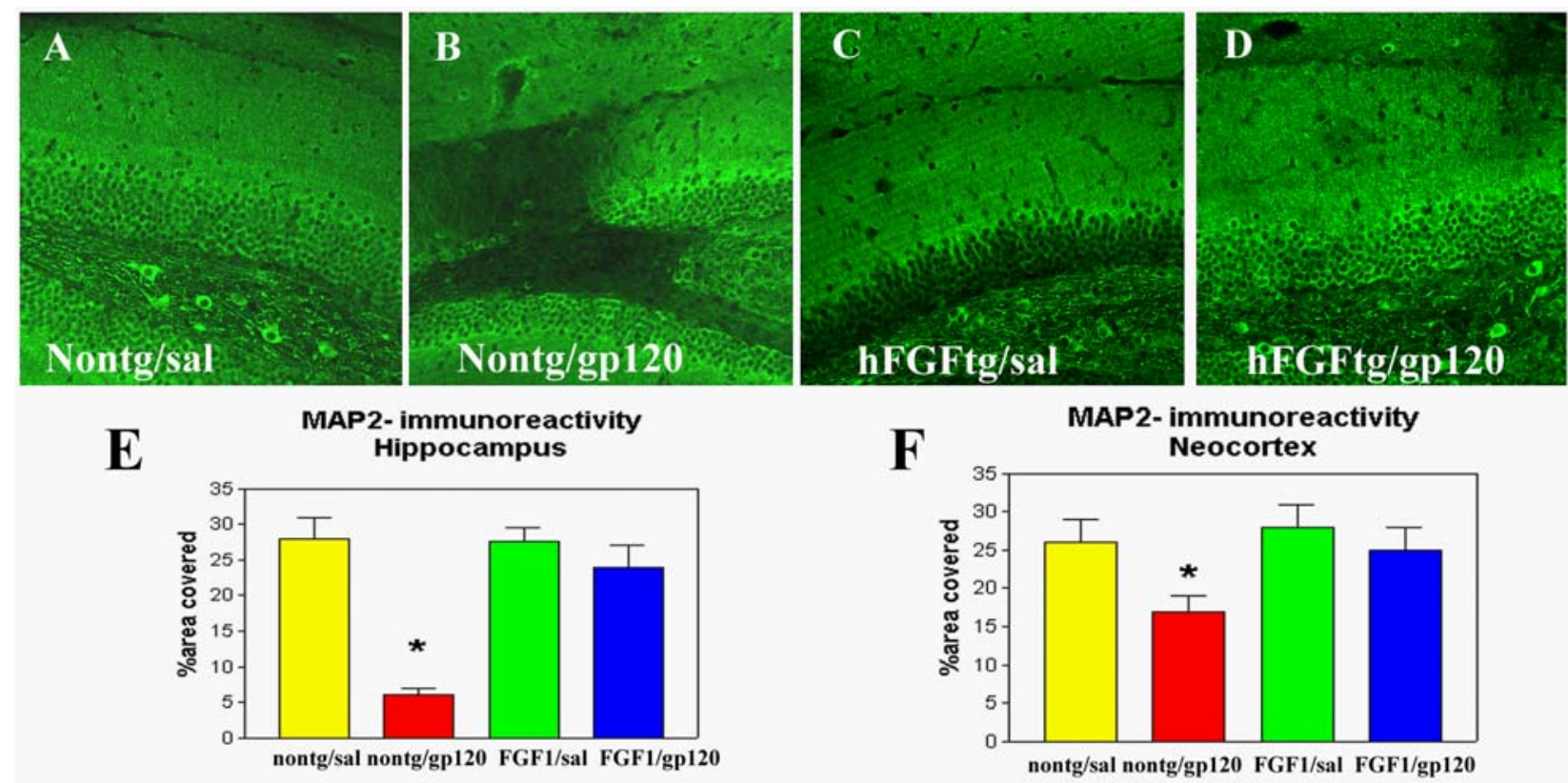

\subsection{Neuroprotective effects of GSK3 $\beta$ inhibition in HIV neurotoxicity}

Similar to FGF1-mediated neuroprotection against HIV toxicity, recent studies have shown that at low concentrations lithium - a GSK3 $\beta$ inhibitor-protects the CNS from toxins [76,77] via GSK3 $\beta$ inactivation. Our previous studies have shown lithium pre-treatment is neuroprotective in mice that received intrahippocampal injections of recombinant gp120 protein [76]. To expand on these studies, and to investigate the protective effects of lithium-mediated regulation of GSK3 $\beta$ against HIV-gp120mediated toxicity in a tg model, mice expressing high levels of gp120 in the brain were treated with lithium and analyzed by immunocytochemistry and immunoblot. For this purpose, 4-month old gp120 tg mice $(\mathrm{n}=6)$ received intraperitoneal injections of lithium chloride (2 mg/kg/day) (Sigma, St. Louis, MO) for 14 days, and 6 control mice received saline injections ( $100 \mu \mathrm{l} /$ day for 14 days).

Consistent with our previous study in lithium-treated mice that received intrahippocampal injections of gp120 [76], lithium treatment in gp120 tg mice protected the hippocampus of mice from gp120-mediated toxicity (Figure 4) [76]. Lithium ameliorated the dendritic damage in gp120 tg mice (Figure 4A-D). Similarly, pre-exposure of neuronal cultures to lithium significantly reduced gp120associated neurotoxicity [76] (Figure 4E). The protective effects of lithium in vitro were partially blocked by LY294002, an inhibitor of the PI3K/Akt/GSK3 $\beta$ pathway (Figure 4E). Immunoblot 
analysis showed that lithium activates Akt and blocks GSK3 $\beta$ activity via phosphorylation at Ser 9 (Figure 4F). This is consistent with previous studies showing that lithium and other inhibitors of GSK3 $\beta$ activation, such as valproic acid, protect the brain against HIV-associated neurotoxicity [7882]. Therefore, the neuroprotective effects of FGF1 and lithium or valproic acid involve targeting analogous pathways, namely the Akt/GSK3 $\beta$ signaling cascade.

Figure 4. Neuroprotective effects of lithium in gp120 models via GSK3 $\beta$ and CDK5 phosphorylation. (a-d) Amelioration of the dendritic pathology (MAP2) in gp120 tg mice treated with lithium (daily injections for 2 weeks). (e) The neuroprotective effects of lithium against gp120 in SH-SY5Y cells are mediated by Akt. (f, g) Lithium downregulates CDK5 hyperactivation and inactivates GSK3 $\beta$ via phosphorylation.
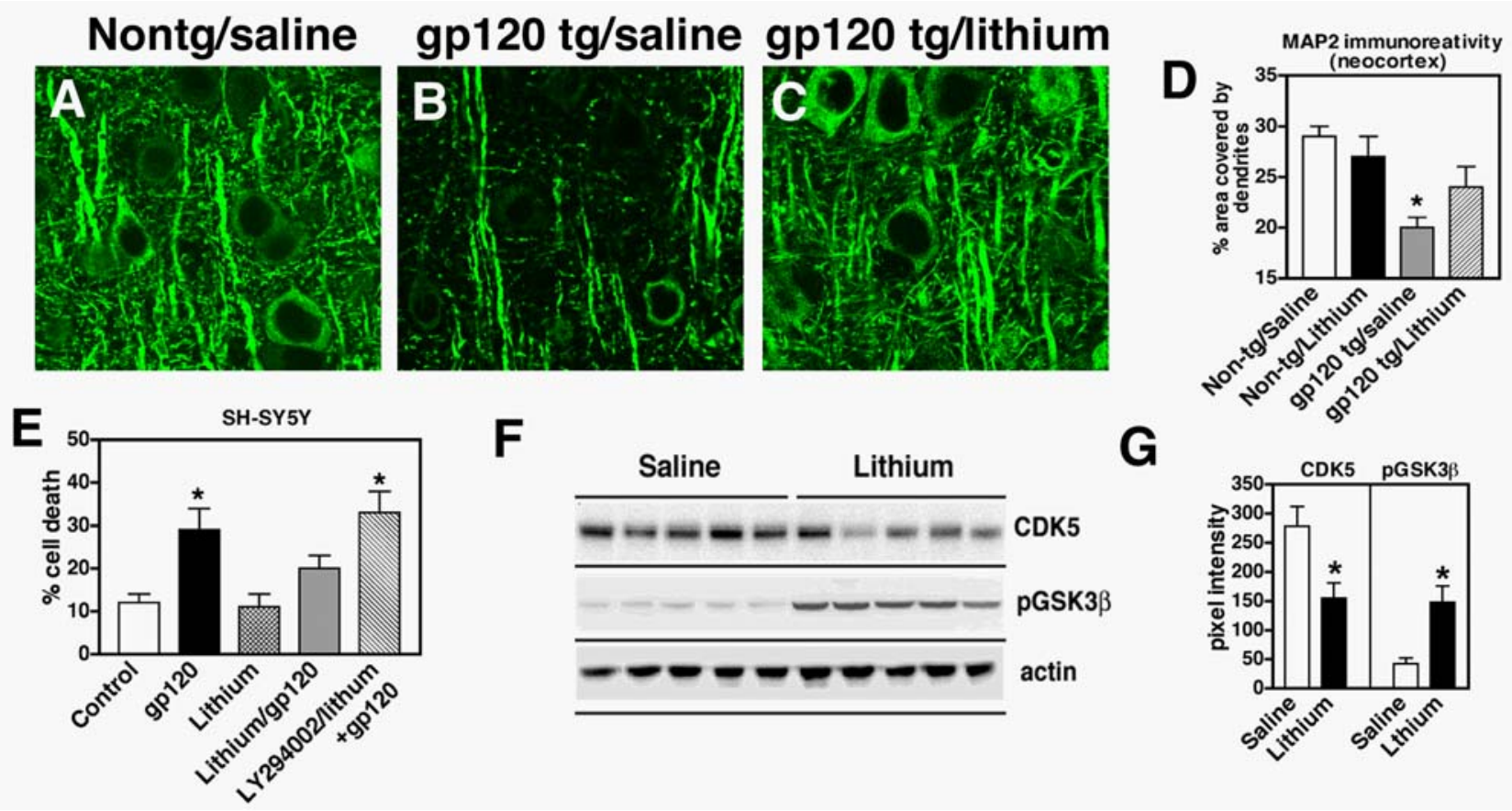

In view of this evidence and previous studies showing that GSK3 $\beta$ activation is involved in the mechanisms of HIV neurotoxicity [60], we concluded that targeting the GSK3 $\beta$ pathway with lithium might be of value in the management of the cognitive impairment [76,81-83]. Remarkably, in a pilot clinical trial we found that treatment with lithium for 12 weeks significantly ameliorated the cognitive deficits in HIV patients [83]. Similarly, another pilot clinical trial demonstrated that valproic acid is well tolerated in patients and can ameliorate HACI $[78,80]$. Taken together, these studies support a role for the GSK3 $\beta$ signaling pathway as a potential therapeutic target in the treatment of neuroAIDS.

Currently, we are in the process of extending the lithium studies as well as investigating the potential therapeutic value of analogous molecules and signaling targets. In this regard, it is becoming clear that the neuroprotective effects of FGF1 and lithium might involve regulation of other signaling cascades [84]. Immunoblot analysis of brain homogenates from gp120 tg mice treated with saline or lithium showed that in addition to activating Akt and blocking GSK3 $\beta$, lithium treatment also resulted in reduced levels of CDK5 expression (Figure 4F), but no effects were observed on p38 and SAPK. These findings support the contention that both the PI3K/Akt/GSK3 $\beta$ and the CDK5 signaling 
pathways might be involved in mediating neurotoxicity in HIVE, and that regulation of CDK5 in pathological states might be an important target for neuroprotection.

\subsection{Role of the CDK5 pathway in the mechanisms of synaptic damage in HIVE}

Recently, and as part of a gene array study, we found that several components of the CDK5 signaling pathway are altered in patients with HIVE [85]. Moreover, other studies have shown that activation of CDK5 by calpains contributes to HIV-induced neurotoxicity [58]. In the mature CNS CDK5 is the predominant CDK, and is expressed at high levels in neurons [86]. While in peripheral dividing tissues other CDKs function as regulators of the cell cycle, CDK5 is unique among the CDKs in that its primary role is in regulating the phosphorylation of a multitude of downstream targets involved in cytoskeletal and synaptic function, among other activities [87]. Through its diverse targets, CDK5 plays an important role in critical processes in both the mature and developing brain, including neurogenesis [50,88], neuronal migration [89], and synapse formation and plasticity [87,90,91] (Figure 5).

CDK5 is a Ser-Thr protein kinase with postmitotic activity that phosphorylates KSP motifs on cytoskeletal proteins (MAP1b, tau, NF, nestin, DCX), synaptic proteins (PSD95, synapsin, cadherin) and transcription factors (MEF2) [92-94]. While in dividing neurons CDKs are activated by cyclins, in the nervous system CDK5 is activated by forming a complex with p35 or p39 [93,95] (Figure 5). In contrast to other CDKs, which are inhibited by the cell cycle regulator proteins p21 and p27 (Kip-1) [96], CDK5 activity is regulated primarily by the metabolism of the activating proteins p35 and p39 [97].

Figure 5. Physiological role of p35-CDK5 signaling in neurons. In the brain, CDK5 is the predominant CDK and can be activated by p35/p39 and phosphorylation of p35 by CK1. CDK5 activation, in turn, results in phosphorylation of key substrates involved in synaptic plasticity (PSD95) and neurogenesis (DCX), among other processes.

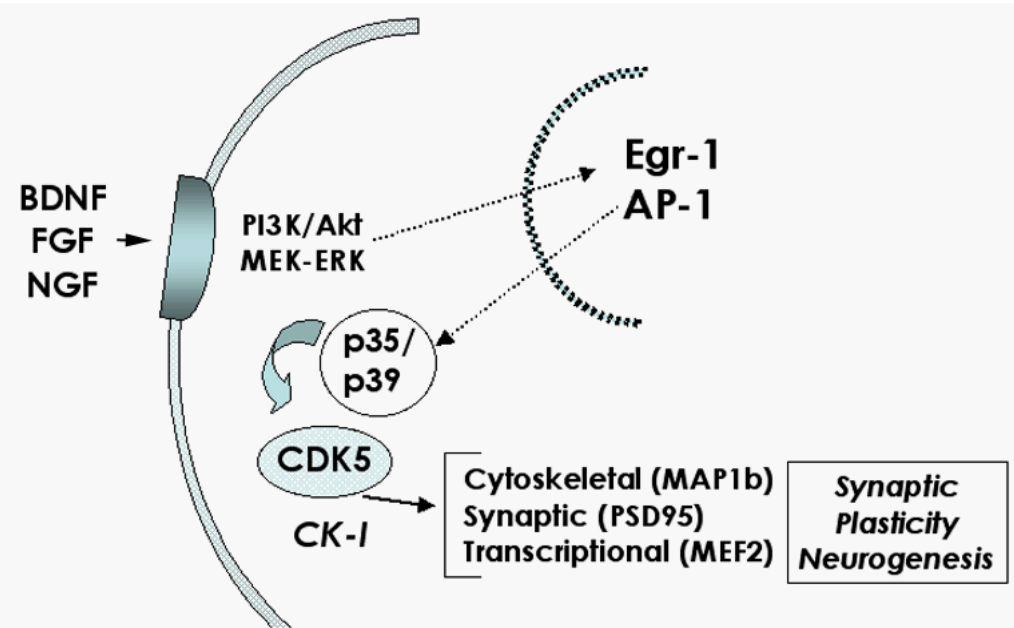

Regulated activation of the CDK5 pathway via p35 [98] plays an important role in neuronal development [99] and synaptic plasticity [86,91] (Figure 5). The p35/p39-CDK5 complex has been shown to be constitutively active, however CDK5 phosphorylation by casein kinase 1 (CK1) [100,101] 
and CDK7 [102] at Ser159 also contribute to CDK5 activation. CDK5 can be further activated by phosphorylation at Tyr15 by Src-related tyrosine kinase [100]. However, it is unclear to what extent phosphorylation plays a role in the regulation of CDK5 activity, and most studies suggest that the primary mechanism controlling CDK5 activation is expression and metabolism of p35 [97].

Synthesis of p35 is stimulated by NGF and BDNF [103] as well as by ECM molecules like laminin [104] (Figure 5). Interestingly, HIV-1 Tat inhibits NGF-induced Egr-1 transcriptional activity and consequent p35 expression in neural cells [57]. The phosphorylation of p35, which is catalyzed by CDK5, produces an upward shift observed by gel electrophoresis and can be utilized as an indicator of CDK5 activity [100]. Although regulated activation of CDK5 by p35 and p39 under physiological conditions promotes neuronal development [99], axonal transport and synaptic activity [86,87,91], recent evidence suggests that abnormal activation of the CDK5 pathway might be also involved in cell death and neurodegeneration [105-108] (Figure 6). In this regard, recent studies indicate that calpain I mediated cleavage of p35 into the N-truncated fragmented p25 results in hyperactivation of CDK5 which in turn results in abnormal phosphorylation of toxic substrates that have been associated with cell death [106] (Figure 6).

Figure 6. Potential mechanisms of HIV-induced neurodegeneration mediated by hyperactivation of CDK5. Activation of cell surface receptors by HIV proteins or cellular neurotoxins causes calcium influx, which might activate calpain and result in p35 cleavage into p25, which in turn hyperactivates CDK5. This leads to aberrant phosphorylation of CDK5 substrates involved in synaptic plasticity (PSD95, synapsin) and neurogenesis (DCX). Alterations in these critical functions might contribute to the underlying neurodegenerative process of HACI.

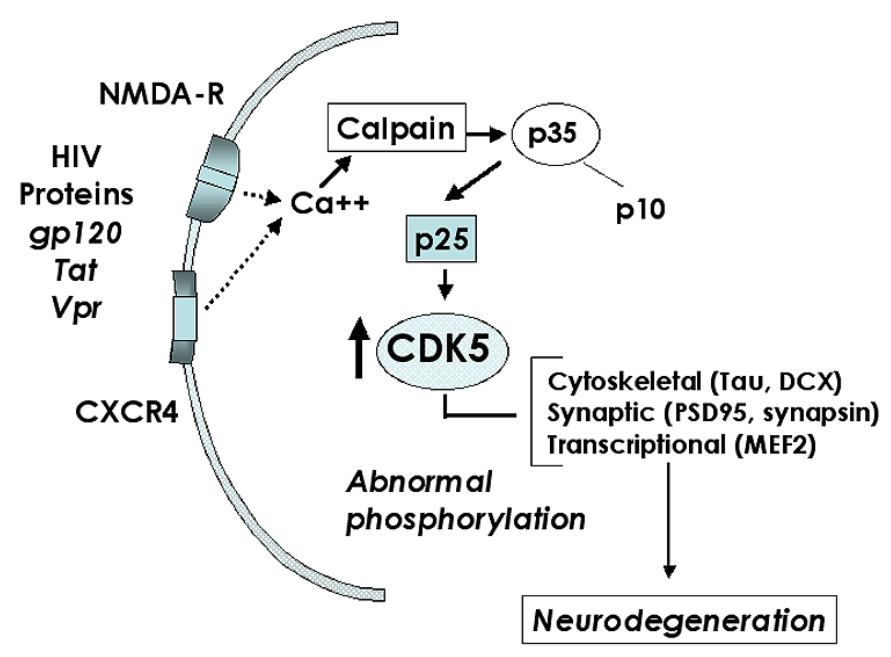

For example, in $\mathrm{AD}$, it has been proposed that amyloid- $\beta(\mathrm{A} \beta)$ protein triggers calpain-mediated cleavage of p35 into p10 and p25, which in turn results in uncontrolled activity of CDK5 and tau hyperphosphorylation [106]. Similarly, in the nervous systems of patients with AIDS, it is possible that HIV products such as gp120 might trigger calcium influx via chemokine or glutamate receptors. This, in turn, may stimulate calpain-mediated proteolysis of p35 into p25 and subsequent hyperactivation of CDK5 with abnormal substrate phosphorylation (Figure 6). Alternatively, HIV proteins might regulate 
CDK5 activity by sequestering p35, or interfering with factors that modulate levels of p35 expression or stability. Since CDK5 plays a role both in synaptic function and neuronal development, then abnormal activation of this molecule by HIV proteins might not only impair the functioning of mature neurons but also contribute to alterations in neurogenesis.

\subsection{CDK inhibitors as potential neuroprotective therapies for HACI}

Although HAART is an indispensable tool for the management of the neurological complications associated with HIV neuro-invasion, this approach does not completely eradicate HIV from the CNS, nor does it provide protection from the neurotoxicity of HIV proteins. Therefore discovery and testing of neuroprotective agents continues to be an important goal as an adjuvant therapy for the cognitive and neurological complications of HIV. Efforts in this direction include the testing of NMDA-R blockers such as memantine [109-111]. In addition, we have recently shown in a pilot clinical trial that modulation of signaling pathways involved in neurodegeneration with lithium might have a potential role as a neuroprotective treatment in HIV patients [83]. Lithium's effects involve regulation of GSK3 $\beta$ and probably CDK5 among other potential targets [84]. Interestingly, and as indicated before, both of these signaling pathways are altered in patients with HIVE. Although lithium $[76,83]$ and valproic acid $[78,80,81]$ might hold some promise as therapeutic regulators of the GSK3 $\beta$ and CDK5 signaling pathways, it is necessary to test and develop new and more specific compounds that target CDK5.

In recent years considerable efforts have been devoted at developing CDK inhibitors for the treatment of neoplastic, viral and neurodegenerative disorders [112]. Among them, roscovitine has been identified as a CDK5 inhibitor with therapeutic potential. This compound belongs to the family of purine-derived CDK inhibitors that includes olomoucine and purvalanols [113]. Roscovitine crosses the blood brain barrier [114] and has been shown to be protective in experimental models of neurotoxicity [115]. This compound has been shown to be safe in humans and in clinical trials for glial cell tumors has been shown to have a promising effect. Roscovitine also blocks to a lesser extent cdc42, CDK2 and ERK [113]. Remarkably, CDK inhibitors are also under development as antiretroviral agents, because HIV recruits these kinases for viral replication in mitotic cells [112]. Of the CDK inhibitors, flavopiridol, which targets CDK1, 2, 4, 7 and 9, in combination with roscovitine, appears to be effective [112]. Thus CDK inhibitors could target both the viral infection as well as the pathogenic mechanism.

\section{Conclusions}

Given that HIV persists in the CNS, then elucidating the signaling pathways involved in mediating the neurotoxic effects of HIV are critical in the development of neuroprotective therapies that might act in conjunction with anti-retroviral therapies. In this context, both the GSK3 $\beta$ and CDK5 signaling cascades mediate some of the neurotoxic effects of HIV proteins (Figure 7). Modulation of these pathways by growth factor (FGF1)-based approaches, or with GSK3 $\beta$ inhibitors (lithium, valproic acid) or CDK5 inhibitors (Roscovitine) holds promise for the development of treatments that may ameliorate the neuropathological effects exerted by HIV proteins. 
Figure 7. Schematic diagram showing the role of the GSK3 $\beta$ and CDK5 signaling pathways in mediating the toxic effects of HIV proteins. HIV proteins and cellular neurotoxins might stimulate the GSK3 $\beta$ and CDK5 signaling pathways via receptor interactions, resulting in the downstream disruption of processes involved in regulating synaptic and neuronal integrity. Growth factors such as FGF1, or other inhibitors of GSK3 $\beta$ signaling, might ameliorate these effects by antagonizing the activation of GSK3 $\beta$ by HIV proteins and cellular neurotoxins. GSK3 $\beta$ and CDK5 share several downstream targets (e.g. Tau), and simultaneous activation of both of these pathways may exacerbate the neurotoxic effects of HIV proteins.

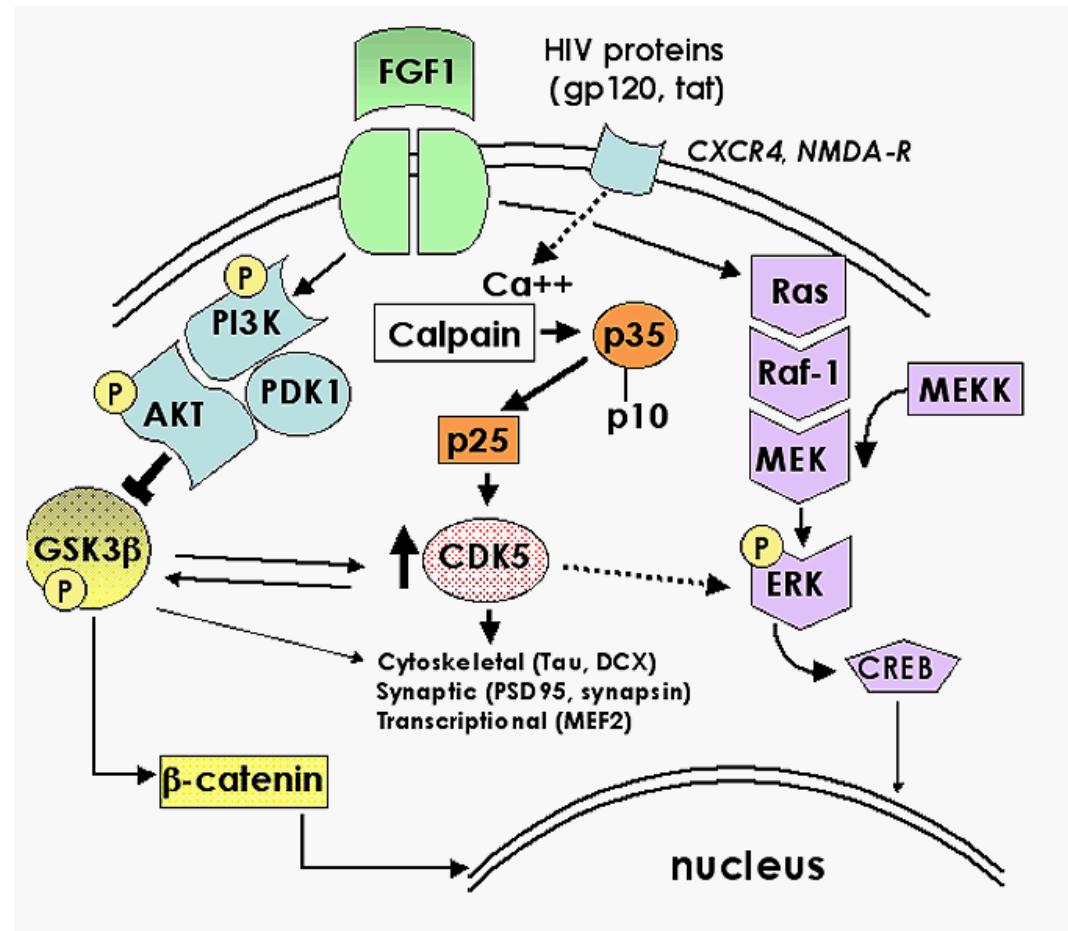

\section{Acknowledgements}

This work was supported by NIH grants MH076681, MH79881, MH45294, MH5974, MH58164, and DA12065, California NeuroAIDS Tissue Network U01 MH83506. The HIV Neurobehavioral Research Center (HNRC) is supported by Center award MH 62512 from NIMH.

\section{References and Notes}

1. Gonzalez-Scarano, F.; Martin-Garcia, J. The neuropathogenesis of AIDS. Nat. Rev. Immunol. 2005, 5, 69-81.

2. Gendelman, H.E.; Persidsky, Y.; Ghorpade, A.; Limoges, J.; Stins, M.; Fiala, M.; Morrisett, R. The neuropathogenesis of the AIDS dementia complex. Aids 1997, 11 (Suppl A), S35-S45.

3. Heaton, R.; Grant, I.; Butters, N.; White, D.; Kirson, D.; Atkinson, J.; McCutchan, J.; Taylor, M.; Kelly, M.; Ellis, R.; Wolfson, T.; Velin, R.; Marcotte, T.; Hesselink, J.; Jernigan, T.; Cahndler, J.; Wallace, M.; Abramson, I.; Group, H. The HNRC 500 - neuropsychology of HIV infection at different disease stages. J. Int. Neuropsych. Soc. 1995, 1, 231-251. 
4. Cherner, M.; Masliah, E.; Ellis, R.J.; Marcotte, T.D.; Moore, D.J.; Grant, I.; Heaton, R.K. Neurocognitive dysfunction predicts postmortem findings of HIV encephalitis. Neurology 2002, 59, 1563-1567.

5. Wiley, C.; Achim, C. HIV encephalitis is the pathologic correlate of dementia in AIDS. Ann. Neurol. 1994, 36, 673-676.

6. Everall, I.P.; Hansen, L.A.; Masliah, E. The shifting patterns of HIV encephalitis neuropathology. Neurotox. Res. 2005, 8, 51-61.

7. Bell, J.E. An update on the neuropathology of HIV in the HAART era. Histopathology 2004, 45, 549-559.

8. Gray, F.; Chretien, F.; Vallat-Decouvelaere, A.V.; Scaravilli, F. The changing pattern of HIV neuropathology in the HAART era. J. Neuropathol. Exp. Neurol. 2003, 62, 429-440.

9. McArthur, J.C.; Haughey, N.; Gartner, S.; Conant, K.; Pardo, C.; Nath, A.; Sacktor, N. Human immunodeficiency virus-associated dementia: an evolving disease. J. Neurovirol. 2003, 9, 205221.

10. Sacktor, N.; McDermott, M.P.; Marder, K.; Schifitto, G.; Selnes, O.A.; McArthur, J.C.; Stern, Y.; Albert, S.; Palumbo, D.; Kieburtz, K.; De Marcaida, J.A.; Cohen, B.; Epstein, L. HIVassociated cognitive impairment before and after the advent of combination therapy. $J$. Neurovirol. 2002, 8, 136-142.

11. Maschke, M.; Kastrup, O.; Esser, S.; Ross, B.; Hengge, U.; Hufnagel, A. Incidence and prevalence of neurological disorders associated with HIV since the introduction of highly active antiretroviral therapy (HAART). J. Neurol. Neurosurg. Psychiatry 2000, 69, 376-380.

12. Lawrence, D.M.; Major, E.O. HIV-1 and the brain: connections between HIV-1-associated dementia, neuropathology and neuroimmunology. Microbes Infect. 2002, 4, 301-308.

13. Diesing, T.S.; Swindells, S.; Gelbard, H.; Gendelman, H.E. HIV-1-associated dementia: a basic science and clinical perspective. AIDS Read. 2002, 12, 358-368.

14. Wiley, C.A. Detection of HIV-1 DNA in microglia/macrophages, astrocytes and neurons isolated from brain tissue with HIV-1 encephalitis by laser capture microdissection. Brain Pathol. 2003, 13, 415; author reply: 415-416.

15. Mirra, S.; del Rio, C. The fine structure of acquired immunodeficiency syndrome encephalopathy. Arch. Pathol. Lab. Med. 1989, 113, 858-865.

16. Pulliam, L.; Herndier, B.; Tang, N.; McGrath, M. Human immunodeficiency virus-infected macrophages produce soluble factors that cause histological and neurochemical alterations in cultured human brains. J. Clin. Invest. 1991, 87, 503-512.

17. Gendelman, H.; Lipton, S.; Tardieu, M.; Bukrinsky, M.; Nottet, H. The neuropathogenesis of HIV-1 infection. J. Leukocyte Biol. 1994, 56, 389-398.

18. Langford, D.; Masliah, E. Crosstalk between components of the blood brain barrier and cells of the CNS in microglial activation in AIDS. Brain Pathol. 2001, 11, 306-312.

19. Minagar, A.; Shapshak, P.; Fujimura, R.; Ownby, R.; Heyes, M.; Eisdorfer, C. The role of macrophage/microglia and astrocytes in the pathogenesis of three neurologic disorders: HIVassociated dementia, Alzheimer disease, and multiple sclerosis. J. Neurol Sci. 2002, 202, 13-23.

20. Speth, C.; Dierich, M.P.; Sopper, S. HIV-infection of the central nervous system: the tightrope walk of innate immunity. Mol. Immunol. 2005, 42, 213-228. 
21. Nath, A. Pathobiology of human immunodeficiency virus dementia. Semin. Neurol. 1999, 19, 113-127.

22. Bellizzi, M.J.; Lu, S.M.; Masliah, E.; Gelbard, H.A. Synaptic activity becomes excitotoxic in neurons exposed to elevated levels of platelet-activating factor. J. Clin. Invest. 2005, 115, 31853192.

23. Nath, A. Human immunodeficiency virus (HIV) proteins in neuropathogenesis of HIV dementia. J. Infect. Dis. 2002, 186 (Suppl 2), S193-S198.

24. Kaul, M.; Lipton, S.A. Chemokines and activated macrophages in HIV gp120-induced neuronal apoptosis. Proc. Natl. Acad. Sci. USA 1999, 96, 8212-8216.

25. Meucci, O.; Fatatis, A.; Simen, A.A.; Bushell, T.J.; Gray, P.W.; Miller, R.J. Chemokines regulate hippocampal neuronal signaling and gp120 neurotoxicity. Proc. Natl. Acad. Sci. USA 1998, 95, 14500-14505.

26. Sanders, V.J.; Pittman, C.A.; White, M.G.; Wang, G.; Wiley, C.A.; Achim, C.L. Chemokines and receptors in HIV encephalitis. Aids 1998, 12, 1021-1026.

27. Giulian, D.; Vaca, K.; Noonan, C. Secretion of neurotoxins by mononuclear phagocytes infected with HIV-1. Science 1990, 250, 1593-1596.

28. Pulliam, L.; Zhou, M.; Stubblebine, M.; Bitler, C.M. Differential modulation of cell death proteins in human brain cells by tumor necrosis factor $\alpha$ and platelet activating factor. $J$. Neurosci. Res. 1998, 54, 530-538.

29. Pulliam, L.; Clarke, J.A.; McGuire, D.; McGrath, M.S. Investigation of HIV-infected macrophage neurotoxin production from patients with AIDS dementia. Adv. Neuroimmunol. 1994, 4, 195-198.

30. Wang, Z.; Trillo-Pazos, G.; Kim, S.Y.; Canki, M.; Morgello, S.; Sharer, L.R.; Gelbard, H.A.; Su, Z.Z.; Kang, D.C.; Brooks, A.I.; Fisher, P.B.; Volsky, D.J. Effects of human immunodeficiency virus type 1 on astrocyte gene expression and function: potential role in neuropathogenesis. $J$. Neurovirol. 2004, 10 (Suppl 1), 25-32.

31. Brandimarti, R.; Khan, M.Z.; Fatatis, A.; Meucci, O. Regulation of cell cycle proteins by chemokine receptors: A novel pathway in human immunodeficiency virus neuropathogenesis? $J$. Neurovirol. 2004, 10 (Suppl 1), 108-112.

32. Martin-Garcia, J.; Kolson, D.L.; Gonzalez-Scarano, F. Chemokine receptors in the brain: their role in HIV infection and pathogenesis. Aids 2002, 16, 1709-1730.

33. Brew, B.; Rosenblum, M.; Cronin, K.; Price, R. AIDS dementia comples and HIV-1 brain infection: clinical-virological correlations. Ann. Neurol. 1995, 38, 563-570.

34. Glass, J.; Fedor, H.; Wesselingh, S.; McArthur, J. Immunocytochemical quantification of human immunodeficiency virus in the brain: correlations with dementia. Ann. Neurol. 1995, 38, 755-762.

35. McArthur, J.C.; McClernon, D.R.; Cronin, M.F.; Nance-Sproson, T.E.; Saah, A.J.; St Clair, M.; Lanier, E.R. Relationship between human immunodeficiency virus-associated dementia and viral load in cerebrospinal fluid and brain. Ann. Neurol. 1997, 42, 689-698.

36. Masliah, E.; Heaton, R.K.; Marcotte, T.D.; Ellis, R.J.; Wiley, C.A.; Mallory, M.; Achim, C.L.; McCutchan, J.A.; Nelson, J.A.; Atkinson, J.H.; Grant, I. Dendritic injury is a pathological 
substrate for human immunodeficiency virus-related cognitive disorders. HNRC Group. The HIV Neurobehavioral Research Center. Ann. Neurol. 1997, 42, 963-972.

37. Masliah, E.; Ge, N.; Achim, C.; Wiley, C. Differential vulnerability of calbindin-immunoreactive neurons in HIV encephalitis. J. Neuropathol. Exp. Neurol. 1995, 54, 350-357.

38. Langford, T.D.; Letendre, S.L.; Marcotte, T.D.; Ellis, R.J.; McCutchan, J.A.; Grant, I.; Mallory, M.E.; Hansen, L.A.; Archibald, S.; Jernigan, T.; Masliah, E. Severe, demyelinating leukoencephalopathy in AIDS patients on antiretroviral therapy. AIDS 2002, 16, 1019-1029.

39. Moore, D.J.; Masliah, E.; Rippeth, J.D.; Gonzalez, R.; Carey, C.L.; Cherner, M.; Ellis, R.J.; Achim, C.L.; Marcotte, T.D.; Heaton, R.K.; Grant, I. Cortical and subcortical neurodegeneration is associated with HIV neurocognitive impairment. Aids 2006, 20, 879-887.

40. Tran, P.B.; Miller, R.J. HIV-1, chemokines and neurogenesis. Neurotox. Res. 2005, 8, 149-158.

41. Krathwohl, M.D.; Kaiser, J.L. HIV-1 promotes quiescence in human neural progenitor cells. $J$. Infect. Dis. 2004, 190, 216-226.

42. Lawrence, D.M.; Durham, L.C.; Schwartz, L.; Seth, P.; Maric, D.; Major, E.O. Human immunodeficiency virus type 1 infection of human brain-derived progenitor cells. J. Virol. 2004, 78, 7319-7328.

43. van Marle, G.; Antony, J.M.; Silva, C.; Sullivan, A.; Power, C. Aberrant cortical neurogenesis in a pediatric neuroAIDS model: neurotrophic effects of growth hormone. Aids 2005, 19, 17811791.

44. Gage, F.H.; Kempermann, G.; Palmer, T.D.; Peterson, D.A.; Ray, J. Multipotent progenitor cells in the adult dentate gyrus. J. Neurobiol. 1998, 36, 249-266.

45. Aimone, J.B.; Wiles, J.; Gage, F.H. Potential role for adult neurogenesis in the encoding of time in new memories. Nat. Neurosci. 2006, 9, 723-727.

46. Olson, A.K.; Eadie, B.D.; Ernst, C.; Christie, B.R. Environmental enrichment and voluntary exercise massively increase neurogenesis in the adult hippocampus via dissociable pathways. Hippocampus 2006, 16, 250-260.

47. Bruel-Jungerman, E.; Laroche, S.; Rampon, C. New neurons in the dentate gyrus are involved in the expression of enhanced long-term memory following environmental enrichment. Eur. J. Neurosci. 2005, 21, 513-521.

48. Brown, J.; Cooper-Kuhn, C.M.; Kempermann, G.; Van Praag, H.; Winkler, J.; Gage, F.H.; Kuhn, H.G. Enriched environment and physical activity stimulate hippocampal but not olfactory bulb neurogenesis. Eur. J. Neurosci. 2003, 17, 2042-2046.

49. Lie, D.C.; Colamarino, S.A.; Song, H.J.; Desire, L.; Mira, H.; Consiglio, A.; Lein, E.S.; Jessberger, S.; Lansford, H.; Dearie, A.R.; Gage, F.H. Wnt signalling regulates adult hippocampal neurogenesis. Nature 2005, 437, 1370-1375.

50. Jessberger, S.; Aigner, S.; Clemenson, G.D. Jr.; Toni, N.; Lie, D.C.; Karalay, O.; Overall, R.; Kempermann, G.; Gage, F.H. Cdk5 regulates accurate maturation of newborn granule cells in the adult hippocampus. PLoS Biol. 2008, 6, e272.

51. Kaul, M.; Garden, G.A.; Lipton, S.A. Pathways to neuronal injury and apoptosis in HIVassociated dementia. Nature 2001, 410, 988-994. 
52. Haughey, N.J.; Nath, A.; Mattson, M.P.; Slevin, J.T.; Geiger, J.D. HIV-1 Tat through phosphorylation of NMDA receptors potentiates glutamate excitotoxicity. J. Neurochem. 2001, 78, 457-467.

53. Maragos, W.F.; Young, K.L.; Turchan, J.T.; Guseva, M.; Pauly, J.R.; Nath, A.; Cass, W.A. Human immunodeficiency virus-1 Tat protein and methamphetamine interact synergistically to impair striatal dopaminergic function. J. Neurochem. 2002, 83, 955-963.

54. Turchan, J.; Pocernich, C.B.; Gairola, C.; Chauhan, A.; Schifitto, G.; Butterfield, D.A.; Buch, S.; Narayan, O.; Sinai, A.; Geiger, J.; Berger, J.R.; Elford, H.; Nath, A. Oxidative stress in HIV demented patients and protection ex vivo with novel antioxidants. Neurology 2003, 60, 307-314.

55. Haughey, N.J.; Mattson, M.P. Calcium dysregulation and neuronal apoptosis by the HIV-1 proteins Tat and gp120. J. Acquir. Immune Defic. Syndr. 2002, 31 (Suppl 2), S55-61.

56. Mattson, M.P. Oxidative stress, perturbed calcium homeostasis, and immune dysfunction in Alzheimer's disease. J. Neurovirol. 2002, 8, 539-550.

57. Darbinian, N.; Darbinyan, A.; Czernik, M.; Peruzzi, F.; Khalili, K.; Reiss, K.; Gordon, J.; Amini, S. HIV-1 Tat inhibits NGF-induced Egr-1 transcriptional activity and consequent p35 expression in neural cells. J. Cell. Physiol. 2008, 216, 128-134.

58. Wang, Y.; White, M.G.; Akay, C.; Chodroff, R.A.; Robinson, J.; Lindl, K.A.; Dichter, M.A.; Qian, Y.; Mao, Z.; Kolson, D.L.; Jordan-Sciutto, K.L. Activation of cyclin-dependent kinase 5 by calpains contributes to human immunodeficiency virus-induced neurotoxicity. J. Neurochem. 2007, 103, 439-455.

59. Sui, Z.; Sniderhan, L.F.; Fan, S.; Kazmierczak, K.; Reisinger, E.; Kovacs, A.D.; Potash, M.J.; Dewhurst, S.; Gelbard, H.A.; Maggirwar, S.B. Human immunodeficiency virus-encoded Tat activates glycogen synthase kinase- $3 \beta$ to antagonize nuclear factor-kappaB survival pathway in neurons. Eur. J. Neurosci. 2006, 23, 2623-2634.

60. Maggirwar, S.B.; Tong, N.; Ramirez, S.; Gelbard, H.A.; Dewhurst, S. HIV-1 Tat-mediated activation of glycogen synthase kinase-3 $\beta$ contributes to Tat-mediated neurotoxicity. $J$. Neurochem. 1999, 73, 578-586.

61. Lannuzel, A.; Barnier, J.V.; Hery, C.; Huynh, V.T.; Guibert, B.; Gray, F.; Vincent, J.D.; Tardieu, M. Human immunodeficiency virus type 1 and its coat protein gp120 induce apoptosis and activate JNK and ERK mitogen-activated protein kinases in human neurons. Ann. Neurol. 1997, 42, 847-856.

62. Rusnati, M.; Urbinati, C.; Musulin, B.; Ribatti, D.; Albini, A.; Noonan, D.; Marchisone, C.; Waltenberger, J.; Presta, M. Activation of endothelial cell mitogen activated protein kinase ERK(1/2) by extracellular HIV-1 Tat protein. Endothelium 2001, 8, 65-74.

63. Hashimoto, M.; Sagara, Y.; Everall, I.P.; Mallory, M.; Everson, A.; Langford, D.; Masliah, E. Fibroblast growth factor 1 regulates signaling via the GSK3 $\beta$ pathway: implications for neuroprotection. J. Biol. Chem. 2002, 277, 32985-32991.

64. Langford, D.; Hurford, R.; Hashimoto, M.; Digicaylioglu, M.; Masliah, E. Signalling crosstalk in FGF2-mediated protection of endothelial cells from HIV-gp120. BMC Neurosci. 2005, 6 (1), 8.

65. Tong, N.; Sanchez, J.F.; Maggirwar, S.B.; Ramirez, S.H.; Guo, H.; Dewhurst, S.; Gelbard, H.A.

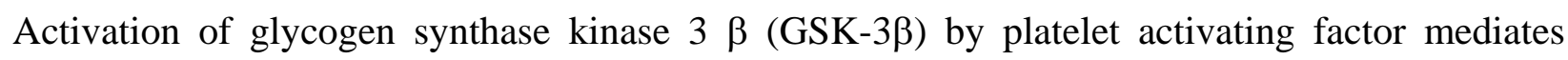


migration and cell death in cerebellar granule neurons. Eur. J. Neurosci. 2001, 13, 1913-1922.

66. Alirezaei, M.; Watry, D.D.; Flynn, C.F.; Kiosses, W.B.; Masliah, E.; Williams, B.R.; Kaul, M.; Lipton, S.A.; Fox, H.S. Human immunodeficiency virus-1/surface glycoprotein 120 induces apoptosis through RNA-activated protein kinase signaling in neurons. J. Neurosci. 2007, 27, 11047-11055.

67. Del Corno, M.; Liu, Q.H.; Schols, D.; de Clercq, E.; Gessani, S.; Freedman, B.D.; Collman, R.G. HIV-1 gp120 and chemokine activation of Pyk2 and mitogen-activated protein kinases in primary macrophages mediated by calcium-dependent, pertussis toxin-insensitive chemokine receptor signaling. Blood 2001, 98, 2909-2916.

68. Yi, Y.; Lee, C.; Liu, Q.H.; Freedman, B.D.; Collman, R.G. Chemokine receptor utilization and macrophage signaling by human immunodeficiency virus type 1 gp120: Implications for neuropathogenesis. J. Neurovirol. 2004, 10 (Suppl 1), 91-96.

69. Everall, I.P.; Trillo-Pazos, G.; Bell, C.; Mallory, M.; Sanders, V.; Masliah, E. Amelioration of neurotoxic effects of HIV envelope protein gp120 by fibroblast growth factor: a strategy for neuroprotection. J. Neuropathol. Exp. Neurol. 2001, 60, 293-301.

70. Sanders, V.; Everall, I.P.; Johnson, R.W.; Masliah, E.; Group, t. H. Fibroblast growth factor modulates HIV co-receptor expression by neural cells. J. Neurosci. Res. 2000, 59, 671-679.

71. Reuss, B.; von Bohlen und Halbach, O. Fibroblast growth factors and their receptors in the central nervous system. Cell. Tissue Res. 2003, 313, 139-157.

72. Presta, M.; Dell'Era, P.; Mitola, S.; Moroni, E.; Ronca, R.; Rusnati, M. Fibroblast growth factor/fibroblast growth factor receptor system in angiogenesis. Cytokine Growth Factor Rev. 2005, 16, 159-178.

73. Langford, D.; Masliah, E. Role of trophic factors on neuroimmunity in neurodegenerative infectious diseases. J. Neurovirol. 2002, 8, 625-638.

74. Brady, M.J.; Bourbonais, F.J.; Saltiel, A.R. The activation of glycogen synthase by insulin switches from kinase inhibition to phosphatase activation during adipogenesis in 3T3-L1 cells. $J$. Biol.Chem. 1998, 273, 14063-14066.

75. Saito, Y.; Vandenheede, J.R.; Cohen, P. The mechanism by which epidermal growth factor inhibits glycogen synthase kinase 3 in A431 cells. Biochem. J. 1994, 303 (Pt 1), 27-31.

76. Everall, I.P.; Bell, C.; Mallory, M.; Langford, D.; Adame, A.; Rockestein, E.; Masliah, E. Lithium ameliorates HIV-gp120-mediated neurotoxicity. Mol. Cell. Neurosci. 2002, 21, 493-501.

77. Rockenstein, E.; Torrance, M.; Adame, A.; Mante, M.; Bar-on, P.; Rose, J.B.; Crews, L.; Masliah, E. Neuroprotective effects of regulators of the glycogen synthase kinase-3 $\beta$ signaling pathway in a transgenic model of Alzheimer's disease are associated with reduced amyloid precursor protein phosphorylation. J. Neurosci. 2007, 27, 1981-1991.

78. Dewhurst, S.; Maggirwar, S.B.; Schifitto, G.; Gendelman, H.E.; Gelbard, H.A. Glycogen

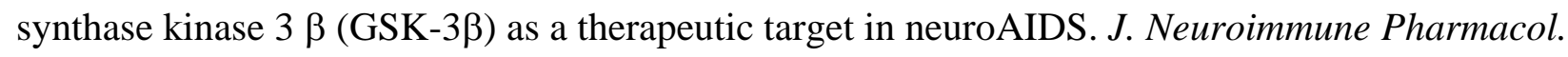
2007, 2, 93-96.

79. Ances, B. M.; Letendre, S.L.; Alexander, T.; Ellis, R.J. Role of psychiatric medications as adjunct therapy in the treatment of HIV associated neurocognitive disorders. Int. Rev. Psychiatry 2008, 20, 89-93. 
80. Schifitto, G.; Peterson, D.R.; Zhong, J.; Ni, H.; Cruttenden, K.; Gaugh, M.; Gendelman, H.E.; Boska, M.; Gelbard, H. Valproic acid adjunctive therapy for HIV-associated cognitive impairment: a first report. Neurology 2006, 66, 919-921.

81. Dou, H.; Ellison, B.; Bradley, J.; Kasiyanov, A.; Poluektova, L.Y.; Xiong, H.; Maggirwar, S.; Dewhurst, S.; Gelbard, H.A.; Gendelman, H.E. Neuroprotective mechanisms of lithium in murine human immunodeficiency virus-1 encephalitis. J. Neurosci. 2005, 25, 8375-8385.

82. Dou, H.; Birusingh, K.; Faraci, J.; Gorantla, S.; Poluektova, L.Y.; Maggirwar, S.B.; Dewhurst, S.; Gelbard, H.A.; Gendelman, H.E. Neuroprotective activities of sodium valproate in a murine model of human immunodeficiency virus-1 encephalitis. J. Neurosci. 2003, 23, 9162-9170.

83. Letendre, S.L.; Woods, S.P.; Ellis, R.J.; Atkinson, J.H.; Masliah, E.; van den Brande, G.; Durelle, J.; Grant, I.; Everall, I. Lithium improves HIV-associated neurocognitive impairment. Aids 2006, 20, 1885-1888.

84. Jorda, E.G.; Verdaguer, E.; Canudas, A.M.; Jimenez, A.; Garcia de Arriba, S.; Allgaier, C.; Pallas, M.; Camins, A. Implication of cyclin-dependent kinase 5 in the neuroprotective properties of lithium. Neuroscience 2005, 134, 1001-1011.

85. Masliah, E.; Roberts, E.S.; Langford, D.; Everall, I.; Crews, L.; Adame, A.; Rockenstein, E.; Fox, H.S. Patterns of gene dysregulation in the frontal cortex of patients with HIV encephalitis. J. Neuroimmunol. 2004, 157, 163-175.

86. Fischer, A.; Sananbenesi, F.; Spiess, J.; Radulovic, J. Cdk5 in the adult non-demented brain. Curr. Drug Targets CNS Neurol. Disord. 2003, 2, 375-381.

87. Johansson, J.U.; Lilja, L.; Chen, X.L.; Higashida, H.; Meister, B.; Noda, M.; Zhong, Z.G.; Yokoyama, S.; Berggren, P.O.; Bark, C. Cyclin-dependent kinase 5 activators p35 and p39 facilitate formation of functional synapses. Brain Res. Mol. Brain Res. 2005, 138, 215-227.

88. Lagace, D.C.; Benavides, D.R.; Kansy, J.W.; Mapelli, M.; Greengard, P.; Bibb, J.A.; Eisch, A.J. Cdk5 is essential for adult hippocampal neurogenesis. Proc. Natl. Acad. Sci. USA 2008, 105, 18567-18571.

89. Xie, Z.; Sanada, K.; Samuels, B.A.; Shih, H.; Tsai, L.H. Serine 732 phosphorylation of FAK by Cdk5 is important for microtubule organization, nuclear movement, and neuronal migration. Cell 2003, 114, 469-482.

90. Samuels, B.A.; Hsueh, Y.P.; Shu, T.; Liang, H.; Tseng, H.C.; Hong, C.J.; Su, S.C.; Volker, J.; Neve, R.L.; Yue, D.T.; Tsai, L.H. Cdk5 promotes synaptogenesis by regulating the subcellular distribution of the MAGUK family member CASK. Neuron. 2007, 56, 823-837.

91. Fischer, A.; Sananbenesi, F.; Pang, P.T.; Lu, B.; Tsai, L.H. Opposing roles of transient and prolonged expression of p25 in synaptic plasticity and hippocampus-dependent memory. Neuron. 2005, 48, 825-838.

92. Tang, X.; Wang, X.; Gong, X.; Tong, M.; Park, D.; Xia, Z.; Mao, Z. Cyclin-dependent kinase 5 mediates neurotoxin-induced degradation of the transcription factor myocyte enhancer factor 2. J. Neurosci. 2005, 25, 4823-4834.

93. Dhavan, R.; Tsai, L.H. A decade of CDK5. Nat. Rev. Mol. Cell Biol. 2001, 2, 749-759.

94. Shelton, S.B.; Johnson, G.V. Cyclin-dependent kinase-5 in neurodegeneration. J. Neurochem. 2004, 88, 1313-1326.

95. Smith, D.S.; Greer, P.L.; Tsai, L.H. Cdk5 on the brain. Cell Growth Differ. 2001, 12, 277-283. 
96. Sherr, C.J.; Roberts, J.M. CDK inhibitors: positive and negative regulators of G1-phase progression. Genes Dev. 1999, 13, 1501-12.

97. Hisanaga, S.; Saito, T. The regulation of cyclin-dependent kinase 5 activity through the metabolism of p35 or p39 Cdk5 activator. Neurosignals 2003, 12, 221-229.

98. Ko, J.; Humbert, S.; Bronson, R.T.; Takahashi, S.; Kulkarni, A.B.; Li, E.; Tsai, L.H. p35 and p39 are essential for cyclin-dependent kinase 5 function during neurodevelopment. J. Neurosci. 2001, 21, 6758-6771.

99. Cicero, S.; Herrup, K. Cyclin-dependent kinase 5 is essential for neuronal cell cycle arrest and differentiation. J. Neurosci. 2005, 25, 9658-9668.

100. Zhu, Y.S.; Saito, T.; Asada, A.; Maekawa, S.; Hisanaga, S. Activation of latent cyclin-dependent kinase 5 (Cdk5)-p35 complexes by membrane dissociation. J. Neurochem. 2005, 94, 1535-1545.

101. Sharma, P.; Sharma, M.; Amin, N.D.; Albers, R.W.; Pant, H.C. Regulation of cyclin-dependent kinase 5 catalytic activity by phosphorylation. Proc. Natl. Acad. Sci. USA 1999, 96, 11156-11160.

102. Rosales, J.; Han, B.; Lee, K.Y. Cdk7 functions as a cdk5 activating kinase in brain. Cell. Physiol. Biochem. 2003, 13, 285-296.

103. Tokuoka, H.; Saito, T.; Yorifuji, H.; Wei, F.; Kishimoto, T.; Hisanaga, S. Brain-derived neurotrophic factor-induced phosphorylation of neurofilament-H subunit in primary cultures of embryo rat cortical neurons. J. Cell Sci. 2000, 113 (Pt 6), 1059-1068.

104. Paglini, G.; Pigino, G.; Kunda, P.; Morfini, G.; Maccioni, R.; Quiroga, S.; Ferreira, A.; Caceres, A. Evidence for the participation of the neuron-specific CDK5 activator P35 during lamininenhanced axonal growth. J. Neurosci. 1998, 18, 9858-9869.

105. Copani, A.; Uberti, D.; Sortino, M.A.; Bruno, V.; Nicoletti, F.; Memo, M. Activation of cellcycle-associated proteins in neuronal death: a mandatory or dispensable path? Trends Neurosci. 2001, 24, 25-31.

106. Patrick, G.N.; Zukerberg, L.; Nikolic, M.; de la Monte, S.; Dikkes, P.; Tsai, L.H. Conversion of p35 to p25 deregulates Cdk5 activity and promotes neurodegeneration. Nature 1999, 402, 615622.

107. Neve, R.L.; McPhie, D.L. The cell cycle as a therapeutic target for Alzheimer's disease. Pharmacol. Ther. 2006, 111, 99-113.

108. Lee, M.S.; Kwon, Y.T.; Li, M.; Peng, J.; Friedlander, R.M.; Tsai, L.H. Neurotoxicity induces cleavage of p35 to p25 by calpain. Nature 2000, 405, 360-364.

109. Nath, A.; Haughey, N.J.; Jones, M.; Anderson, C.; Bell, J.E.; Geiger, J.D. Synergistic neurotoxicity by human immunodeficiency virus proteins Tat and gp120: protection by memantine. Ann. Neurol. 2000, 47, 186-194.

110. Alisky, J.M. Could cholinesterase inhibitors and memantine alleviate HIV dementia? J. Acquir. Immune Defic. Syndr. 2005, 38, 113-114.

111. Manji, H.; Miller, R. The neurology of HIV infection. J. Neurol. Neurosurg. Psychiatry 2004, 75 (Suppl 1), i29-35.

112. Schang, L.M. Cyclin-dependent kinases as cellular targets for antiviral drugs. J. Antimicrob. Chemother. 2002, 50, 779-792. 
113. Schwartz, G.K.; Shah, M.A. Targeting the cell cycle: a new approach to cancer therapy. J. Clin. Oncol. 2005, 23, 9408-9421.

114. Vita, M.; Abdel-Rehim, M.; Olofsson, S.; Hassan, Z.; Meurling, L.; Siden, A.; Siden, M.; Pettersson, T.; Hassan, M. Tissue distribution, pharmacokinetics and identification of roscovitine metabolites in rat. Eur. J. Pharm. Sci. 2005, 25, 91-103.

115. Di Giovanni, S.; Movsesyan, V.; Ahmed, F.; Cernak, I.; Schinelli, S.; Stoica, B.; Faden, A.I. Cell cycle inhibition provides neuroprotection and reduces glial proliferation and scar formation after traumatic brain injury. Proc. Natl. Acad. Sci. USA 2005, 102, 8333-8338.

(C) 2009 by the authors; licensee Molecular Diversity Preservation International, Basel, Switzerland. This article is an open-access article distributed under the terms and conditions of the Creative Commons Attribution license (http://creativecommons.org/licenses/by/3.0/). 